\title{
Comparative study of Global, European and Italian Standards on Hydrogen Refueling Stations
}

\author{
Matteo Genovese ${ }^{1^{*}}$, Viviana Cigolotti $^{2}$, Elio Jannelli ${ }^{3}$ and Petronilla Fragiacomo $^{1}$ \\ ${ }^{1}$ Department of Mechanical, Energy and Management Engineering, University of Calabria, \\ Arcavacata di Rende, 87036 Cosenza, Italy \\ ${ }^{2}$ Laboratory for Energy Storage, Batteries and Hydrogen Production and Utilization Technologies, \\ Department of Energy Technologies and Renewable Sources, ENEA-Italian National Agency for \\ New Technologies, Energy and Sustainable Economic Development, Research Centre of Portici, \\ 80055 Naples, Italy \\ ${ }^{3}$ Department of Engineering, University of Naples “Parthenope”, Centro Direzionale Is. C4, 80143 \\ Naples, Italy
}

\begin{abstract}
The purpose of this paper is to give a strategic overview of the existing standards governing the construction and operation of hydrogen refueling stations. A succinct and comprehensive study of hydrogen refueling station standards globally, in Europe, and in Italy is conducted and discussed in light of the new European Hydrogen Strategy and Roadmap. Among the numerous topics examined, a particular emphasis is placed on the standards in force for on-site hydrogen production via water electrolysis, hydrogen storage, both liquid and gaseous, and refueling protocols for lightduty and heavy-duty vehicles, on an international level through the provision of ISO, IEC, and SAE standards; on a European level through the examination of the CEN/CENELEC database; and on an Italian national level through the analysis of the UNI database.
\end{abstract}

\section{Introduction}

Hydrogen as an energy carrier has tremendous potential to address a variety of important energy issues in a variety of industries [1]. Its uses contribute to the de-carbonization of different industries, provide a flexible and efficient process [2] and act as long-term energy storage [3].

Hydrogen has the benefit of being a versatile energy carrier that enables energy generation with little or no environmental effect in a wide variety of industries that presently rely on fossil fuels. Hydrogen is certainly developing as a viable option that is garnering both academic and industrial interest.

Because transportation accounts for about one-third of worldwide carbon dioxide emissions (which contribute to climate change), hydrogen adoption in the mobility sector, coupled with fuel cell technology, such as in Fuel Cell Electric Vehicles (FCEVs), is

\footnotetext{
* Corresponding author: matteo.genovese@unical.it
} 
worldwide recognized as an alternative fuel able to decrease greenhouse gas emissions in this sector. Additionally, hydrogen may be generated via the process of water electrolysis utilizing clean energy derived from renewable sources, being "green" and "clean" also at the source of production.

Hydrogen refueling stations (HRSs) must undoubtedly be implemented in this scenario. They are at the core of the infrastructure that enables hydrogen-based green mobility, serving as the hub for the distribution required to support the delivery of hydrogen to FCEVs. However, the success of this novel technology is constrained by some impediments to future growth and development. The most important disadvantages to this endeavor are a lack of sufficient infrastructure and a hefty initial investment cost, as well as the lack of established regulations, codes, and standards compared to other alternative fuel infrastructures, such as methane refueling stations and electric chargers.

To the best of the authors' knowledge, the latest scientific contribution on the HRS regulations and standards belongs to 2017, when Pique et al. [4] compared the laws, norms, and standards applicable to hydrogen fueling stations for light-duty vehicles. The analysis was based on 2014 data, with documents gathered through a bibliographic review and information gathered via a questionnaire distributed to authorities and IA HySafe [5] members.

Another European Project, HyLaw [6], addressed a similar issue, extended to commercial adoption of hydrogen and fuel cell technologies by providing market developers with a comprehensive understanding of relevant laws and drawing policymakers' attention to legal obstacles that need to be eliminated. The latest report [7] presented a short and overall legislative summary on HRS regulations and standards, followed by an assessment and the proposal of some recommendations.

A specific overview of standards related to HRS equipment and operation is lacking in literature, and it could be helpful to researchers, policymakers, and HRS operators to support the future HRS network expansion.

To address this research gap, the present paper aims to provide a high-level strategic overview of the current standards that regulate the design and operation of hydrogen filling stations. A concise and thorough research of hydrogen refueling station standards is performed and reviewed worldwide, in Europe, and in Italy. The standards in force for onsite hydrogen production via water electrolysis, hydrogen storage, both liquid and gaseous, and refueling protocols are among the numerous topics examined, on an international, European, and Italian level.

\section{HRS Standards}

Regulation, codes, and standards development is a key action needed to facilitate safe and accelerated access to the market for HRS components and technologies.

The present paper is based on the following classification on standards, codes, and regulations:

- A standard is a formal document that specifies the requirements for a certain component, or that elaborates on a specific technique or approach;

- A code is a document that specifies the desired outcome - what a product should adhere to - rather than the method by which it should be accomplished;

- Regulations are obligatory and mandatory, in contrast to codes and standards, which are voluntary. 


\subsubsection{International Level}

The main international organizations for standard publication are ISO and IEC organizations. Within these organizations (ISO, IEC, and SAE), standards are developed by TC with national involvement from CEN members, called NSBs. The technical committee establishes a working group to complete a particular job by a certain deadline A WG is responsible for the actual standard development (working group). The main TCs for ISO hydrogen-related standards are:

- ISO/TC 197 Hydrogen technologies;

- ISO/TC 220 Cryogenic vessels;

- $\quad$ ISO/TC 58 Gas cylinders;

- ISO/TC 22/SC 41 Specific aspects for gaseous fuels.

Figure 1 shows the main ISO standards for HRS equipment and operation. It is worthy to mention how several standards are still under development, for different components and equipment. Liquid hydrogen storage technologies appear to have a more mature knowledge in terms of ISO standards, while several gaseous hydrogen-related standards, which include most of today and future hydrogen applications, are under drafting and work in progress.

Most IEC standards are focused on fuel cell technologies and their application in power systems. Few of them are centered on HRS operation and equipment. However, useful standards can be found for explosive gas atmospheres, as shown in Figure 2, and they found application in hydrogen station operation.

The main TCs for IEC hydrogen-related standards are:

- $\quad$ IEC/TC 31 - Equipment for explosive atmospheres;

- IEC/TC 69 - Electrical power/energy transfer systems for electrically propelled road vehicles and industrial trucks;

- IEC/TC 105 - Fuel cell technologies.

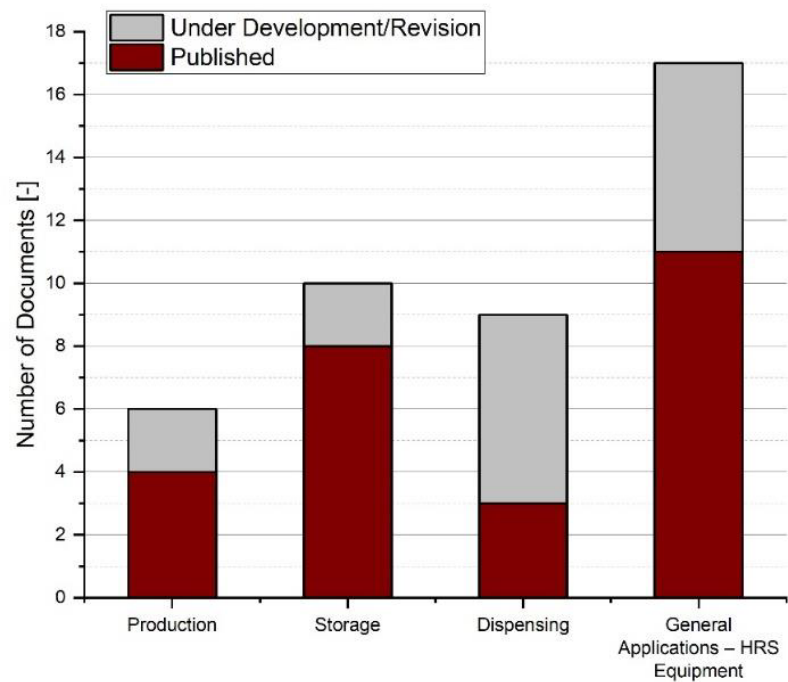

Fig. 1. HRS Equipment - ISO Standards 


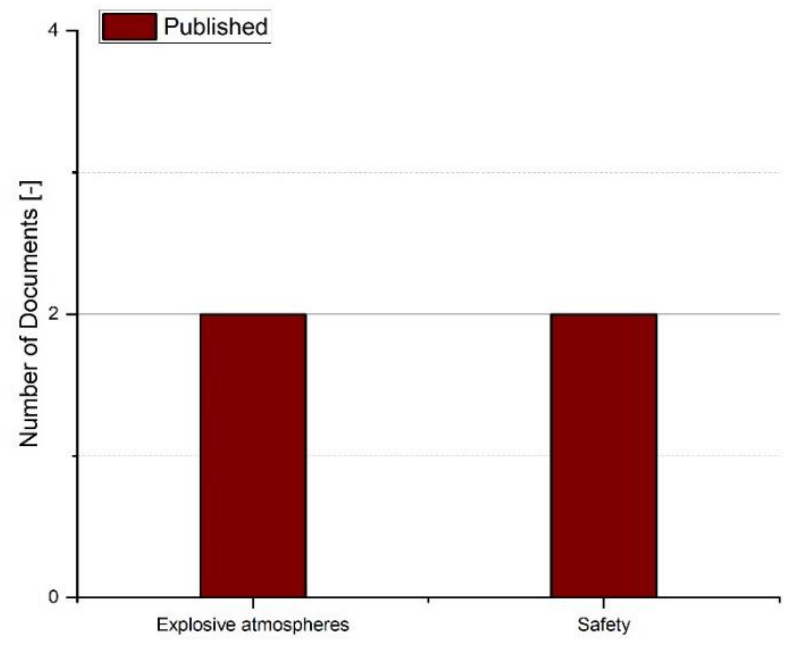

Fig. 2. HRS Equipment - IEC Standard

Apart from ISO and IEC, SAE standards are also available. The Society of Automotive Engineers (SAE) is a worldwide organization of engineers and technical specialists, and it is delivering technical protocols on hydrogen refueling processes and connecting devices, as shown in Figure 3. The main TC for SAE hydrogen-related standards is the SAE Fuel Cell Standards Committee.

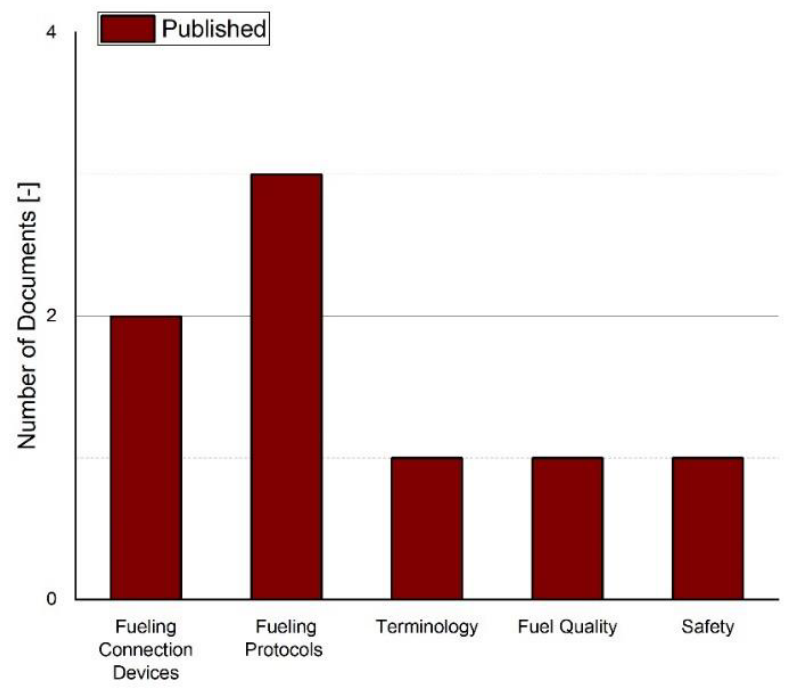

Fig.3. HRS Equipment - SAE 


\subsubsection{European Level}

CEN or CENELEC generate and publish codes and standards at the European level, shown in Figure 4. Part of them is the transposition/implementation of ISO standards.

The main TCs for CEN/CENELEC hydrogen-related standards are:

- $\mathrm{CEN} / \mathrm{CLC} / \mathrm{TC} 6$ - Hydrogen

- $\quad$ CEN/TC 23 Transportable gas cylinder

- $\mathrm{CEN} / \mathrm{TC} 69$ Industrial valves

- $\mathrm{CEN} / \mathrm{TC} 185$ Fasteners

- $\quad$ CEN/TC 197 Pumps

- $\quad$ CEN/TC 234 Gas infrastructure

- $\mathrm{CEN} / \mathrm{TC} 235$ Gas pressure regulators and associated safety devices for use in gas transmission and distribution;

- CEN/TC 236 Non-industrial manually operated shut-off valves for gas and particular combinations valves-other product

- $\quad$ CEN/TC 238 Test gases, test pressures, appliance categories, and gas appliance types

- $\quad$ CEN/TC 268 Cryogenic vessels and specific hydrogen technologies applications

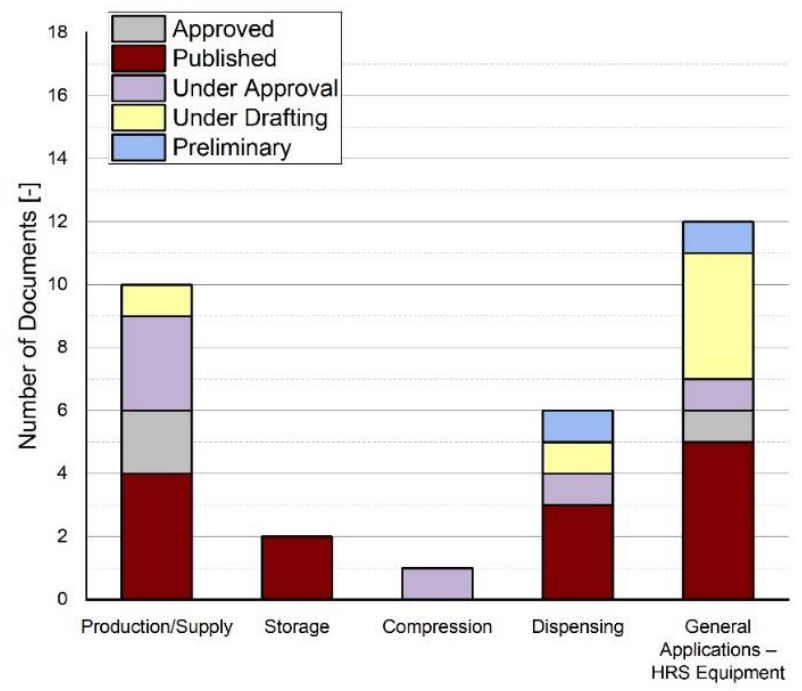

Fig.4. HRS Equipment - CEN/CENELEC

\subsubsection{Italian Legislation}

Considering the abundance of renewable energy sources and the presence of a capillary network for gas transport, Italy is an ideal market for the development of green hydrogen. Italy's geographical location in the Mediterranean makes it an ideal crossroads between Africa and the Middle East, big potential exporters of hydrogen, and the nations of the north, large potential consumers. Despite the huge potential, there are still significant regulatory and other barriers to the full development of green hydrogen in Italy. 
The only TC National mirror group to ISO/TC 197 Hydrogen technologies is the UNI/CT 056/GL 01, which acts also as the national mirror group for CEN/CLC/JTC 6. The Italian TC is focusing on the systems, equipment, and connections used to produce and consume hydrogen from renewable energy sources.

The National Decree n. 1657 of 16 December 2016, which implements the EU Directive 2014/94/EU, recognizes hydrogen as an alternative fuel and commits Italy to develop an appropriate network of refueling stations by December 31, 2025. The lack of the implementing regulations of the Ministerial Decree of 31 August 2006 has caused a major obstacle to the spread of hydrogen refueling stations in Italy. With a new Decree from 2018 , a 700 bar supply pressure is allowed and improved alignment with ISO 19880, the absence of implementing rules for the Ministerial Decree of August 31, 2006, has been overcome. The local "National Fire Corps - Corpo Nazionale dei Vigili del Fuoco" is responsible for giving an evaluation in terms of safety and fire prevention. However, a series of hydrogenrelated actions are excluded, such as:

- $\quad$ the storage and transport of liquid hydrogen;

- $\quad$ safety distances aligned with the operating pressure of the equipment

- $\quad$ adoption of hydrogen supplied via pipelines;

- $\quad$ a methodology for safety distance calculations in case of ignited and un-ignited hydrogen releases;

- mitigation techniques, such as ventilation systems, passive or active.

At the time of writing, the only available national standards belong to UNI, and are:

- $\quad$ UNI ISO 14687:2020, Hydrogen fuel quality -- Product specification, which accepts ISO 14687:2019;

- UNI ISO 19880-1:2020, Gaseous hydrogen -- Fueling stations - Part 1: General requirements, which accepts ISO 19880-1:2020;

- UNI ISO/TR 15916:2018, Basic considerations for the safety of hydrogen systems, which accepts ISO/TR 15916:2015.

\section{Conclusions}

This article presents an extended overview of HRS standards:

- $\quad$ at an international level, by presenting ISO, IEC, and SAE standards;

- $\quad$ at European level, by analyzing the CEN/CENELEC database;

- $\quad$ and at Italian National Level.

As a result of the findings, ISO has developed numerous hydrogen standards for HRS equipment and operation. Quality, safety, production, hydrogen stations, and testing are all covered by ISO hydrogen standards. It's worth mentioning, though, that numerous standards for different components and equipment are in the works right now. Technical protocols for hydrogen refueling procedures and connected devices have previously been published by SAE. The majority of IEC standards relate to fuel cell technology and how it is used in power systems. The International Electrotechnical Commission (IEC) has developed hydrogen standards that concentrate on safety, applications, and testing. Only a small number of standards are focused on HRS operations and equipment. Effective standards, on the other hand, exist for explosive gas atmospheres.

Several European standards are being approved, drafted, or are in the early stages of development. They will, however, be published shortly to keep up with the new European Hydrogen Strategy and Roadmap. 
In Italy, there are uneven and insufficient hydrogen requirements for HRS spreading out at the national level. Standards for hydrogen production, storage, transportation, and fueling should be emphasized, with a comprehensive assessment of the whole supply chain taking into account hydrogen as an energy carrier. This covers how hydrogen is generated, how it is stored on a large scale to account for seasonal intermittency in renewable energy generation, and how it is transported and distributed from a centralized production facility to HRS and within the HRS itself.

\section{Nomenclature}

$\begin{array}{ll}\text { CEN } & \text { European Committee for Standardization } \\ \text { CENELEC } & \text { European committee for Electro-Technical Standardization } \\ \text { EC } & \text { International Electro-Technical Commission } \\ \text { FCEV } & \text { Fuel Cell Electric Vehicle } \\ \mathrm{GH}_{2} & \text { Gaseous Hydrogen } \\ \mathrm{HRS} & \text { Hydrogen Refueling Station } \\ \text { ISO } & \text { International Standards Organization } \\ \mathrm{LH}_{2} & \text { Liquid Hydrogen } \\ \mathrm{NSB} & \text { National Standardization Bodies } \\ \mathrm{SAE} & \text { Society of Automotive Engineers } \\ \mathrm{SM} & \text { Steam Reforming } \\ \text { TC } & \text { Technical Committee } \\ \text { UNI } & \text { Ente Nazionale Italiano di Unificazione } \\ \text { WE } & \text { Water Electrolysis } \\ \text { WG } & \text { Working Group }\end{array}$

\section{References}

1. You, C.; Kim, J. Optimal design and global sensitivity analysis of a $100 \%$ renewable energy sources based smart energy network for electrified and hydrogen cities. Energy Convers. Manag. 2020, 223, 113252 , doi:https://doi.org/10.1016/j.enconman.2020.113252.

2. Abdin, Z.; Mérida, W. Hybrid energy systems for off-grid power supply and hydrogen production based on renewable energy: A techno-economic analysis. Energy Convers. Manag. 2019, doi:10.1016/j.enconman.2019.06.068.

3. Abdalla, A.M.; Hossain, S.; Nisfindy, O.B.; Azad, A.T.; Dawood, M.; Azad, A.K. Hydrogen production, storage, transportation and key challenges with applications: A review. Energy Convers. Manag. 2018.

4. Pique, S.; Weinberger, B.; De-Dianous, V.; Debray, B. Comparative study of regulations, codes and standards and practices on hydrogen fuelling stations. Int. J. Hydrogen Energy 2017, doi:10.1016/j.ijhydene.2016.02.158.

5. IA HySafe International association on hydrogen safety Available online: http://www.hysafe.info/ (accessed on Oct 12, 2021).

6. HyLAW HyLAW Online Database Available online: https://www.hylaw.eu (accessed on Oct 12, 2021).

7. Floristean, A. EU Policy Paper (June 2019) HyLAW; 2019; Vol. 2019;

8. Tolias, I.C.; Giannissi, S.G.; Venetsanos, A.G.; Keenan, J.; Shentsov, V.; Makarov, D.; Coldrick, S.; Kotchourko, A.; Ren, K.; Jedicke, O.; et al. Best practice 
guidelines in numerical simulations and CFD benchmarking for hydrogen safety applications. Int. J. Hydrogen Energy 2019, doi:10.1016/j.ijhydene.2018.06.005.

9. Kim, W.; Shentsov, V.; Makarov, D.; Molkov, V. High pressure hydrogen tank rupture: blast wave and fireball. In Proceedings of the 6th International Conference on Hydrogen Safety; 2015.

10. Sasaki, K.; Li, H.-W.; Hayashi, A.; Yamabe, J.; Ogura, T. Hydrogen Energy Engineering; 2016; ISBN 978-4-431-56040-1.

11. Molkov, V. Fundamentals of Hydrogen Safety Engineering I; 2012; ISBN 9788740302264.

12. Hydrogen Tool Portal Available online: https://h2tools.org/lessons (accessed on Oct 26, 2019).

13. Molkov, V. Hydrogen Safety Research : State-of-the-Art. Proc. 5th Int. Semin. Fire Explos. Hazards 2007.

14. Samsun, R.C.; Antoni, L.; Rex, M. Advanced Fuel Cells Technology Collaboration Programme Report on Mobile Fuel Cell Application: Tracking Market Trends; 2020; 